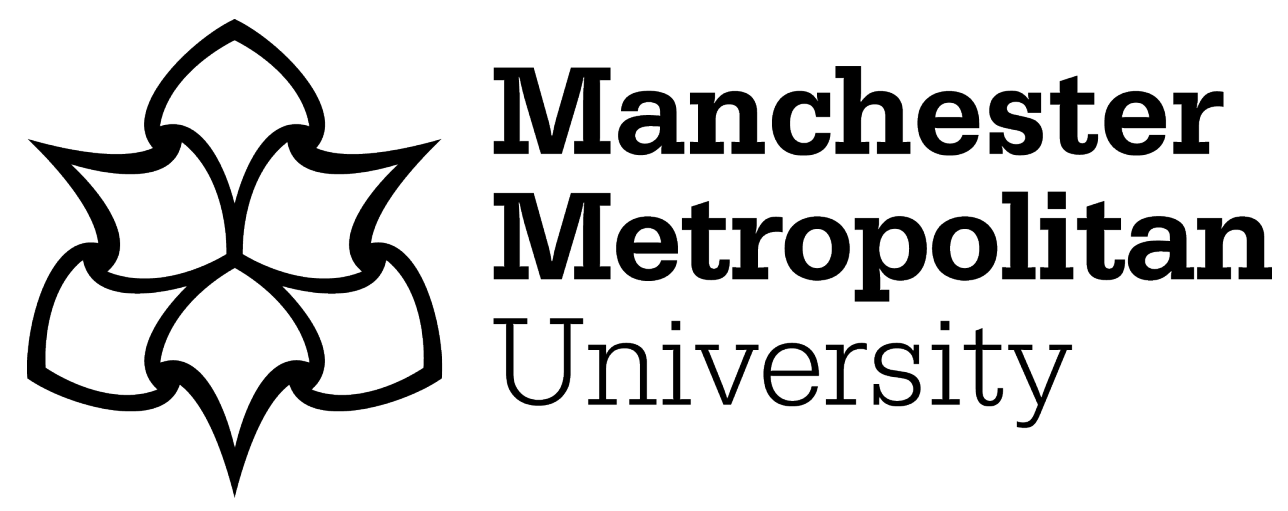

Kroll, MW, Still, GK, Neuman, TS, Graham, MA and Griffin, LV (2017) Acute forces required for datal compression asphyxia: A biomechanical model and historal comparisons. Medicine, Science and the Law, 57 (2). pp. 61-68. ISSN 0025-8024

Downloaded from: https://e-space.mmu.ac.uk/621876/

Version: Accepted Version

Publisher: SAGE Publications

DOI: https://doi.org/10.1177/0025802417695711

Please cite the published version 


\title{
Acute forces required for fatal compression asphyxia: A biomechanical model and historical comparisons
}

\author{
Mark W Kroll', G Keith Still', Tom S Neuman³, \\ Michael A Graham ${ }^{4}$ and Lanny V Griffin ${ }^{5}$
}

\begin{abstract}
Background: Fatalities from acute compression have been reported with soft-drink vending machine tipping, motor vehicle accidents, and trench cave-ins. A major mechanism of such deaths is flail chest but the amount of force required is unclear. Between the range of a safe static chest compression force of $1000 \mathrm{~N}$ (I02 kg with earth gravity) and a lethal dynamic force of $10-20 \mathrm{kN}$ (falling $450 \mathrm{~kg}$ vending machines), there are limited quantitative human data on the force required to cause flail chest, which is a major correlate of acute fatal compression asphyxia.

Methods: We modeled flail chest as bilateral fractures of six adjacent ribs. The static and dynamic forces required to cause such a ribcage failure were estimated using a biomechanical model of the thorax. The results were then compared with published historical records of judicial "pressing," vending machine fatalities, and automobile safety cadaver testing. Results and conclusion: The modeling results suggest that an adult male requires $2550 \pm 250 \mathrm{~N}$ of chest-applied distributed static force $(260 \pm 26 \mathrm{~kg}$ with earth gravity) or $4050 \pm 320 \mathrm{~N}$ of dynamic force to cause flail chest from shortterm chest compression.
\end{abstract}

\section{Keywords}

Flail chest, biomechanics, ribcage, compression asphyxia

\section{Introduction}

There has been some controversy regarding the role of compression asphyxia in arrest-related death. ${ }^{1-4}$ It is incontrovertible that compression asphyxia is a welldocumented cause of death in many circumstances. ${ }^{5-}$

${ }^{11}$ Flail chest caused by compression prevents effective breathing and can cause death even after the compression is removed. ${ }^{12}$

A major mechanism of compression deaths is the generation of flail chest. Vega and Adams reported that $11 / 14$ chest compression asphyxia deaths had rib fractures, and they suggested the use of rib fractures as a marker for such a death. ${ }^{13}$ The goal of our study was to quantify the forces required for the generation of flail chest to assist in the understanding of compression asphyxia; we appreciate that there are other mechanisms that can be involved in compression asphyxia deaths.

Flail chest is a clinical phenomenon that typically is caused by 5-8 broken ribs. ${ }^{14}$ For biomechanical modeling purposes we defined a flail chest injury as requiring three adjacent bilateral rib fractures for a total of six broken ribs.

As a lower safe limit, previous research has found no evidence of rib fractures or clinically significant ventilation effects in prone individuals with a static force up to $1000 \mathrm{~N}$ (102 kg with earth gravity) on the back. ${ }^{15}$

Numerous deaths from falling soda vending machines have been reported. ${ }^{16-18}$ A fully loaded machine typically weighs $450 \mathrm{~kg}$, with most of the mass in the top, and impacts the ground with a velocity of $\sim 2.5 \mathrm{~m} / \mathrm{s}$ and an energy of $\sim 2 \mathrm{~kJ}$. ${ }^{16}$ The force imparted to a supine person is $10-20 \mathrm{kN}$ based on a deceleration distance of $10-20 \mathrm{~cm}$.

Between these outer limits of a non-lethal static force of $1000 \mathrm{~N}(102 \mathrm{~kg})$ and a potentially lethal dynamic force of $10-20 \mathrm{kN}$, there are minimal quantitative human data in the indexed medical literature on flail chest and compression injuries. Existing modeling and cadaver chest-injury research has been

\footnotetext{
'University of Minnesota and California Polytechnic University, USA

${ }^{2}$ Manchester Metropolitan University, Manchester, UK

${ }^{3}$ University of California San Diego, USA

${ }^{4}$ Department of Pathology, St. Louis University, USA

${ }^{5}$ California Polytechnic University, San Luis Obispo, USA
}

Corresponding author:

Mark W Kroll, Box 23 Crystal Bay, MN 55323, USA.

Email: mark@kroll.name 
concentrated on high-velocity impacts seen in automobile crashes. ${ }^{19-21}$ This is of minimal assistance for predicting the risk of flail chest injury in most forensic cases.

Most of the published fatal chest compression cases involve the mass of a car or tractor (typically $>1000 \mathrm{~kg}$ ) compressing the torso, and hence they set a high upper bound on the mass required for ribcage failure. ${ }^{2,23}$ Historical quantitative records exist of judicial "pressing" or the application of chest mass for interrogation or execution that is useful for model validation. ${ }^{24}$ Cadaver car-safety tests of steering-wheel impacts also provide some useful chest compression data. ${ }^{25} \mathrm{We}$ considered all of these data to refine and validate our model.

The objective of our study is to define the force required to compress the chest sufficiently to cause fractures sufficient to result in flail chest.

\section{Modeling methods}

One author (LVG) developed a biomechanical model to predict the static and dynamic forces required for flail chest. The criterion used was bilateral fractures in ribs \#3-5. Due to the bilateral symmetry of the model this, by necessity, was equivalent to having bilateral fractures in the same ribs, hence giving a total of six rib fractures. With this symmetry requirement, our model is slightly more conservative yet slightly more liberal than the American Institute of Surgery definition, which requires only three rib fractures but in two arbitrary locations. ${ }^{26}$

The thoracic region was modeled by assuming that the rib cage was a series of rings with the sternum bridging each rib (Figure 1). Each rib was assumed to be circular in form with uniform mechanical properties and cross-sectional area. The geometric data for the ribs are provided in Table 1.

The load was assumed to be transferred into the ribs by deforming the sternum, and thus the deflection of the ribs depended on the respective deformation of the sternum with respect to the point of load application. For the sake of modeling, the sternum was represented as a uniform cross-section beam that rests on an elastic foundation with a distributed load, while acting on the sternum. As such, the deflection can be calculated using:

$$
y=y_{A} F_{1}+\frac{\theta_{A}}{2 \beta} F_{2}-\frac{W}{4 E l \beta^{3}} F_{\alpha 5}
$$

The terms $y_{A}, \theta_{A}, F_{1}, F_{2}$, and $F_{\alpha 5}$ are functions of position along the beam, $\beta$ is a function of the foundation properties (in this case the ribs), $E$ and $I$ are the

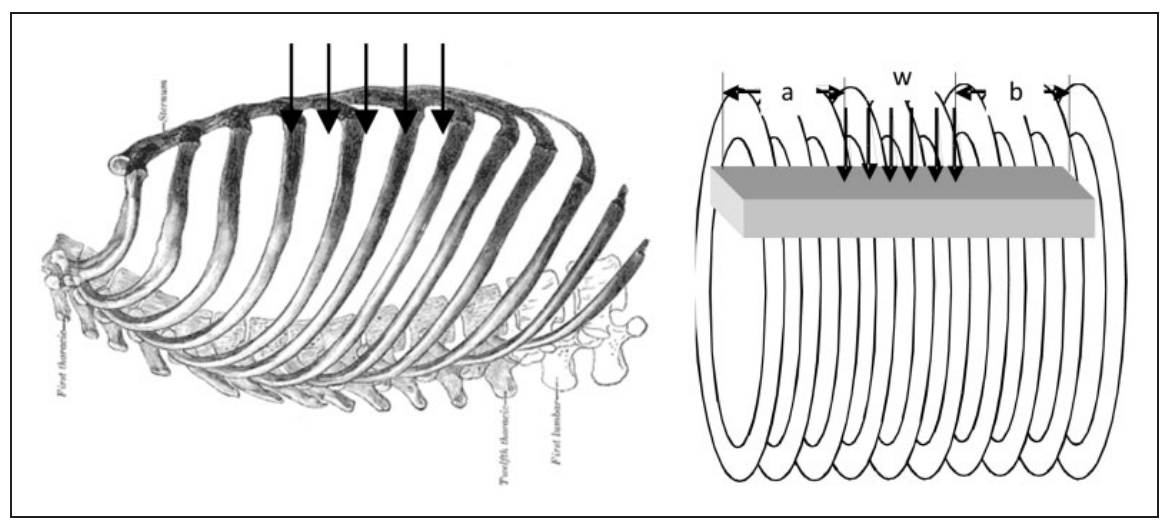

Figure I. A simplified model of the thoracic region with an applied load.

Table I. Geometric and material properties for the ribs.

\begin{tabular}{|c|c|c|c|c|c|c|c|c|c|c|}
\hline & Rib I & Rib 2 & Rib 3 & Rib 4 & Rib 5 & Rib 6 & Rib 7 & Rib 8 & Rib 9 & Rib 10 \\
\hline$A, \mathrm{~mm}^{2}$ & 56.7 & 63.6 & 78.5 & 78.5 & 78.5 & 78.5 & 78.5 & 78.5 & 78.5 & 78.5 \\
\hline$R, \mathrm{~mm}$ & 90.0 & 100.0 & 120.0 & 120.0 & 125.0 & 125.0 & 125.0 & 125.0 & 125.0 & 120.0 \\
\hline do, $\mathrm{mm}$ & 8.5 & 9.0 & 10.0 & 10.0 & 10.0 & 10.0 & 10.0 & 10.0 & 10.0 & 10.0 \\
\hline $\mathrm{e}, \mathrm{mm}$ & 0.05 & 0.05 & 0.05 & 0.05 & 0.05 & 0.05 & 0.05 & 0.05 & 0.05 & 0.05 \\
\hline$E_{d}, \mathrm{GPa}$ & 3646 & 3646 & 3646 & 3646 & 3646 & 3646 & 3646 & 3646 & 3646 & 3646 \\
\hline$E_{s}, \mathrm{GPa}$ & $2.3 \pm 0.6$ & $2.3 \pm 0.6$ & $2.3 \pm 0.6$ & $2.3 \pm 0.6$ & $2.3 \pm 0.6$ & $2.3 \pm 0.6$ & $2.3 \pm 0.6$ & $2.3 \pm 0.6$ & $2.3 \pm 0.6$ & $2.3 \pm 0.6$ \\
\hline$k_{d}, \mathrm{~N} / \mathrm{mm}$ & $8.2 \pm 2.0$ & $7.5 \pm 1.9$ & $6.7 \pm 1.7$ & $6.7 \pm 1.7$ & $5.9 \pm 1.4$ & $5.9 \pm 1.4$ & $5.9 \pm 1.4$ & $5.9 \pm 1.4$ & $5.9 \pm 1.4$ & $6.7 \pm 1.7$ \\
\hline$k_{s}, \mathrm{~N} / \mathrm{mm}$ & $5.4 \pm 1.4$ & $5.0 \pm 1.3$ & $4.4 \pm 1.1$ & $4.4 \pm 1.1$ & $3.9 \pm 1.0$ & $3.9 \pm 1.0$ & $3.9 \pm 1.0$ & $3.9 \pm 1.0$ & $3.9 \pm 1.0$ & $4.4 \pm 1.1$ \\
\hline
\end{tabular}


elastic modulus and cross-sectional moment of inertia of the sternum, and $W$ is the distributed load. ${ }^{27}$ The length of the chest was $180 \mathrm{~mm}$, with a $150 \mathrm{~mm}$ distributed load placed $15 \mathrm{~mm}$ from the manubrium. ${ }^{28}$ Since the stiffness of the ribs varies somewhat from superior to inferior, the stiffness of the ribs was averaged.

The mechanical properties of the ribs were assumed to be uniform. A simple rule of mixtures was used to determine composite mechanical properties of the ribs and sternum by an isostrain rule of mixtures.

$$
E_{\text {eff }}=E_{C} V_{C}+E_{T} V_{T}
$$

Here, $E$ is the elastic modulus, and the subscripts: eff, $C$, and $T$ refer to effective, cortical bone, and trabecular bone, respectively, and $V$ refers to the volume fraction of bone.

The elastic moduli for the bone was estimated using the rate sensitive estimations of Carter and Hayes. $^{29}$

$$
E=3790 \dot{\varepsilon}^{0.06} \rho^{3}
$$

Here, $\dot{\varepsilon}$ is the strain rate and $\rho$ is the apparent density. The density was set so that the cortical bone elastic modulus was $16.0 \pm 2.0 \mathrm{GPa}$ and the trabecular bone modulus was $1.0 \pm 0.25 \mathrm{GPa}$ from Equation 3. The densities determined by Equation 3 were then used in Equation 2 to determine the volume fraction of cortical bone which would be consistent with the data reported by Yoganandan and Pintar ${ }^{30}$ for the average mechanical and geometric properties for bending loads of ribs. The elastic modulus they reported was $2328 \pm 564 \mathrm{MPa}$. To account for this variation in the mechanical properties, we ran the analysis at the mean and both an upper bound of rib elastic modulus at $2900 \mathrm{MPa}$ (mean +1 standard deviation) and a lower bound at $1760 \mathrm{MPa}$ (mean - 1 stdev).

The stiffness of the ribs, $k$, was determined by calculating the ratio of the vertical displacement, $\delta$, to the force, $F$, for a ring subjected to a point load.

$$
k=\frac{F}{\delta}=\frac{E_{e f f} I}{0.15 R^{3}}
$$

Here, $I$ is the cross-sectional moment of inertia for the rib, $E_{\text {eff }}$ was calculated using Equations 2 and 3, and $R$ is the radius of the ribcage. The strength of the bone is also related to the apparent density and strain rate as reported by Carter and Hayes: ${ }^{29}$

$$
\sigma=68 \dot{\varepsilon}^{0.06} \rho^{2}
$$

Equation 5 was used to determine the strength of the cortical bone tissue of the ribs and sternum to estimate when failure would occur. This was done for upper, typical, and lower bounds on properties. The stress in the sternum was calculated using the beam bending equation:

$$
\sigma=\frac{M c}{I}
$$

where $M$ is the applied moment, $c$ is the half-thickness of the beam, and $I$ is the cross-sectional moment of inertia. For the sternum, the moment was calculated using:

$$
M=-y_{A} 2 E I \beta^{2} F_{3}-\theta_{A} E I \beta F_{4}-\frac{w}{2 \beta} F_{\alpha 2}
$$

The rib stress was also determined using:

$$
\sigma=\frac{-w}{2 A}\left[\frac{1+R\left(\frac{d_{o}}{2}-e\right)}{e\left(R-\frac{d_{o}}{2}\right)}\right]
$$

In Equation 8, $W$ is the applied force, $R$ is the radius of the ribcage, $e$ is the eccentricity of the neutral axis, $d_{\mathrm{o}}$ is the outer diameter of the rib, and $A$ is the cross-sectional area of the rib. As stated, we assumed the ribcage was cylindrical and that the ribs were circular in cross-section.

The maximum load that could be carried was determined by setting the force using either Equation 7 for the sternum or Equation 8 for the ribs that would equal the cortical bone strength calculated using Equation 5. We used two different strain rates to simulate either static loading, $\dot{\varepsilon}=0.001 \mathrm{~s}^{-1}$ (a rate slightly less than mechanical testing standards for materials), or dynamic (non-impact) loading, $\dot{\varepsilon}=2 \mathrm{~s}^{-1}$ (which would correspond to $10 \%$ strain over a $50 \mathrm{~ms}$ duration, which is typical of low-velocity motor vehicle accidents and comparable with falling soda machines).

\section{Results}

The loads in the ribs were greater than in the sternum, and so these governed the failure loads. Thus, our model accounts for weight applied to the front or the back of the chest. Our modeling produced values of force denominated in units of newtons. In the static case, a load of $2550 \pm 250 \mathrm{~N}$ was sufficient to cause fractures of the \#3-\#5 ribs on both sides of the sternum (a total of six fractures). Note that the stress distribution and displacement are shown in Figure 2 and both are plotted with respect to position on the sternum, considering the manubrium as the origin. The maximum displacement is $54 \mathrm{~mm}$ and most of the displacement is due to the ribs rather than the sternum. The stress of nearly $20 \mathrm{MPa}$ in the sternal body is highest at the 4th rib where the load is centered and not of sufficient magnitude to fracture the sternal body since the ultimate tensile strength of 


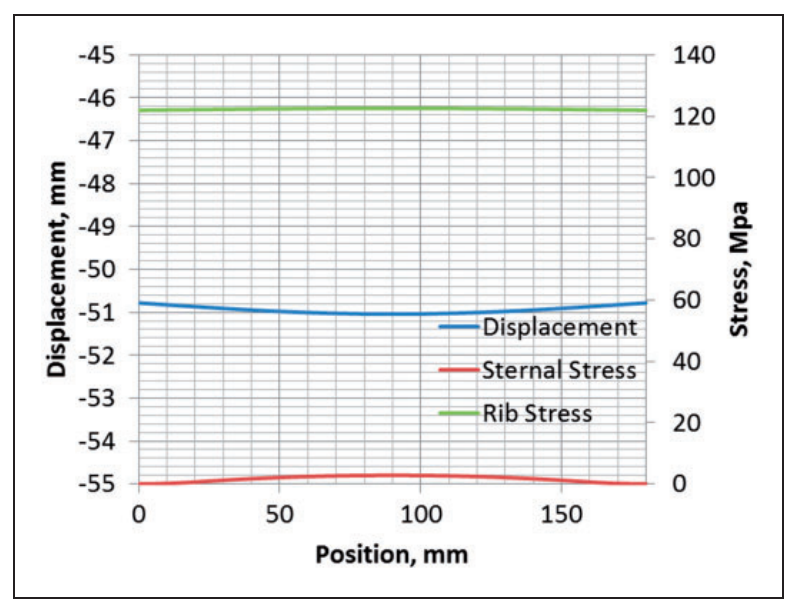

Figure 2. Static loading predictions for the thoracic model under average loads.

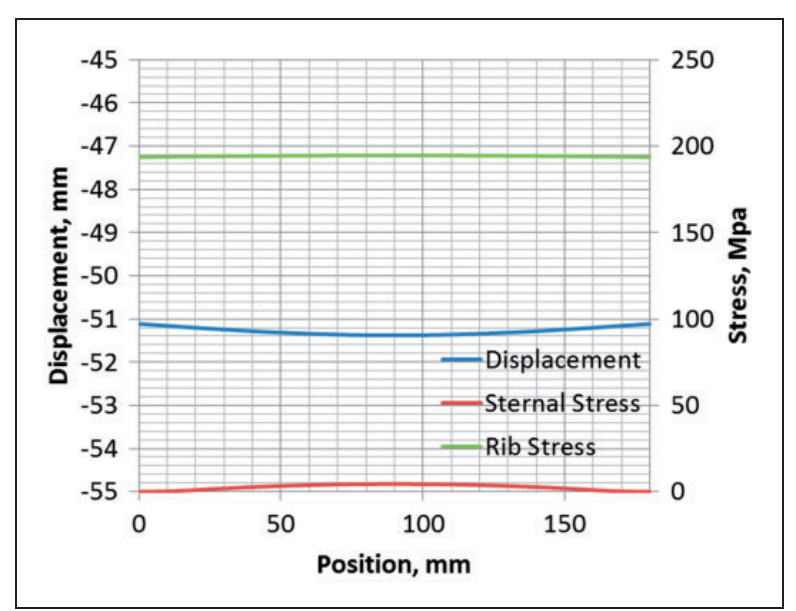

Figure 3. Dynamic loading predictions for the thoracic model.

cortical bone is about $120 \mathrm{MPa}$ in tension. The sternum does not experience a large stress due to the load being distributed over the majority of the length. If the sternum was loaded over a small distance, such as a point load, the stresses in the sternum would be much higher and might result in fracture.

For the dynamic situation, the loads in the ribs were also greater than in the sternum, and thus these governed the failure loads. A force of $4050 \pm 320 \mathrm{~N}$ was sufficient to cause the fracture of six ribs from \#3-\#5. The stress distribution and displacement are shown in Figure 3, and are both plotted with respect to position on the sternum, considering the manubrium as the origin. The maximum displacement is $51 \mathrm{~mm}$. The energy is estimated by integrating the load by the displacement, and is $202 \pm 30 \mathrm{~J}$. The energy to fracture decreases as the load increases because of the viscoelastic nature of the tissue. Therefore, while the strength increases, the displacement to failure decreases. The stress in the sternal

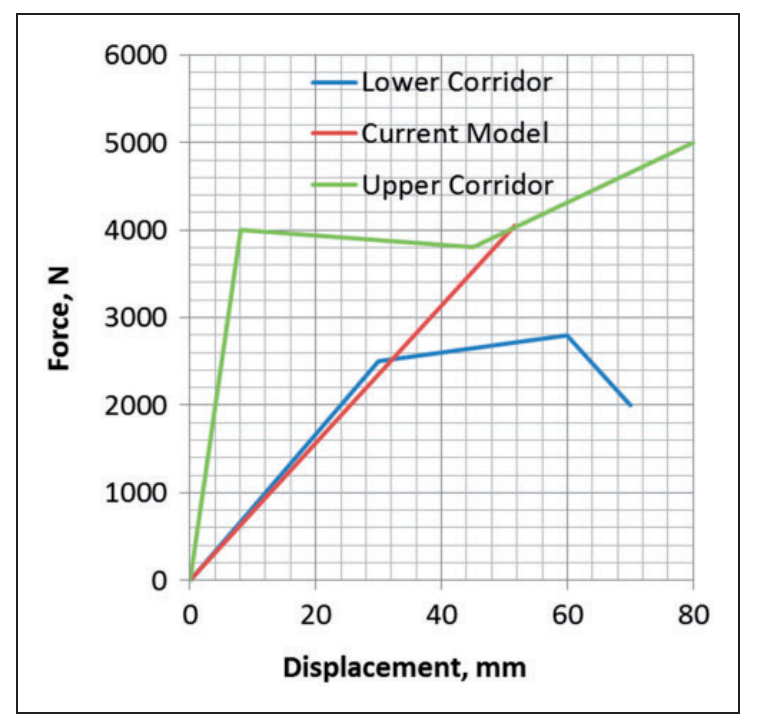

Figure 4. Dynamic loading predictions for the thoracic model subject to impact loading compared with a $23.5 \mathrm{~kg}$ projectile impact to the sternum at $6.5 \mathrm{~m} / \mathrm{s}$.

body is very low (5 MPa), since most of the deformation, under a distributed load, is carried by the ribs.

A test case was run to compare the model performance with cadaver force-deflection data in the carcrash safety testing literature. ${ }^{25}$ Here, the modeled area of impact was centered at rib 4, which was $90 \mathrm{~mm}$ from the manubrium and applied to an area of $20 \mathrm{~mm}$. While the present model does not account for the strong viscoelastic effects that are associated with the tissue, the overall performance of the model is reasonably consistent, as seen in Figure 4. Even though the model under-predicts the failure load and stiffness somewhat, the model does provide a conservative estimate of the behavior, which is favorable for first-order approximations.

We also compared the stiffness data for dynamic response with a more recent cadaveric study involving dynamic, non-impact loading of the thoracic region. ${ }^{31}$ In this case we chose to model the hub, since it is an accepted corridor and the loading is quite similar to our model (Figure 5). Our model over-predicts the lower end of the chest displacement for post-mortem human subjects since we are treating the material as linear elastic, albeit rate sensitive. Despite this, the upper prediction for failure is well within the corridors.

There are several limitations to our model. First, the loading does not allow a broad range of loading conditions which a 3D model would. ${ }^{32}$ The model does not allow for impulsive or inertial affects to be modeled, and it does not capture higher-order effects such as soft tissues and muscular structures. For example, the ribs are cartilaginous at their margins, not bone, and they have irregular areas of energy transfer located at their sternal and vertebral junctions. 


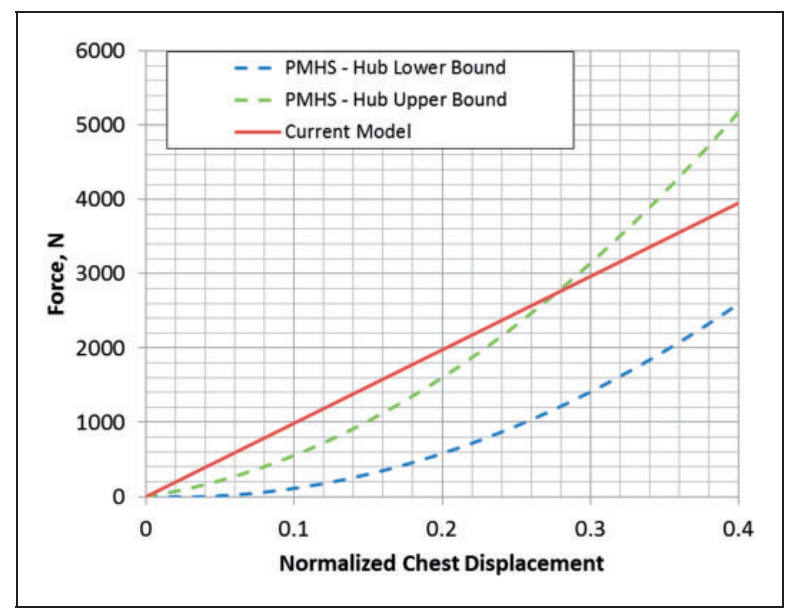

Figure 5. Comparison of the current model predictions for a hub loading condition with cadaver data.

The rib cage is not circular but oval. Using an oval rather than a circular model would affect the foundation constant (beta) slightly for realistic dimensions of an oval; however, the beam displacement is relatively insensitive to the foundation constant.

Data used in our modeling were derived from measurements made in normal adult males. Validation is lacking for adult females, children and persons having bone diseases, most notably osteoporosis.

Despite the limitations, the model is a good firstorder approximation. It is much easier to use than a 3D finite element model and the results can be computed using a spreadsheet. ${ }^{33}$ The model does provide a reasonable $2 \mathrm{D}$ approximation to more sophisticated models. Finally, the model does capture dynamic rate effects and shows good agreement with available data.

\section{Historical record review}

While the chest compression volunteer data is limited to $1000 \mathrm{~N}(102 \mathrm{~kg})$, the former practice of judicial "pressing" provides limited but well-documented validation data since real-time records were kept by an officer of the court as part of the judicial process. The descriptions of the facial signs and symptoms and of diaphragmatic breathing are very helpful in the context of our model. See the excellent review article by McKenzie for more details. ${ }^{24}$ The original spellings and units are maintained here for historical flavor.

Edward Burnworth refused to plead, ... the Press laid upon him, which he continued for the Space of one Hour and three Minutes, under the Weight of three Hundred, three Quarters, and two Pounds; ... the High-Sheriff himself was present, and frequently exhorted him to plead to the Indictment, which at last he consented to do....

Nathaniel Hawes, 20, highway robbery: ... When he had lain about seven Minutes in the Press, under a Weight of $250 \mathrm{lb}$. he desired to be carried back, which the Court granting, ... the Bruises he received thereby on the Chest, pained him so exceedingly during the short remainder of his Life, that he was hardly able to perform those Devotions which the near approach of death, made him desirous to offer up for so profligate a Life.

William Spiggot and Thomas Phillips, alias Cross, highway robbery: As soon as they entered the PressRoom Phillips desired, that he might return to the Bar and plead; but Spiggot continuing obstinate was put under the Press. He bore 350 Pounds Weight for half an Hour. In the Midst of his Groans, he sometimes lay silent, as if Insensible of Pain; then would fetch his Breath very quick and fast. Two or three Times, he complained that hey had laid a cruel Weight on his Face; tho' nothing was upon his Face, ... which might be occasion'd by the Blood being flush'd and forc'd up into his Face; and pressing as violently against the Veins and small Tendrills there, as if the Pressure upon them had been externally on his Face. When he had continu'd about half an Hour ... and 50 pounds more of Weight had been laid on his Breast, he told the Justice of Peace ... That he would Plead. Accordingly, the Weights were at once taken off, ..On Monday, February 9, before the Execution, he receiv'd the Sacrament; and said .... that he could raise his breath only in the lower Part of the Stomach.

John Weekes of Horsham was charged with robbery and murder of a woman ... They laid on him 100 weight, then added 100 more, and he still continued obstinate; they then added 100 more, which made 300 lb. weight, yet he would not speak; $50 \mathrm{lb}$. more was added, when he was nearly dead, having all the agonies of death upon him; then the executioner, who weighed about 16 or 17 stone, laid down upon the board which was over him, and, adding to the weight, killed him in an instant.

Note: Assuming a body mass of 16.5 stone $(163.3 \mathrm{~N} /$ stone), and that $80 \%$ of the executioner's mass was applied to the board, the added mass was $84 \mathrm{~kg}$ $(824 \mathrm{~N})$ for a total of $243 \mathrm{~kg}(2384 \mathrm{~N})$.

The only recorded female death by pressing was that of Clitherow. ${ }^{34}$ She was a Catholic martyr and was pressed to death in 1583 under "a quantity of seven or eight hundred-weight at the least," dying in "one quarter of an hour": a relatively swift execution (however unenviable) expedited by "a sharp stone, as much as a man's fist."

The pressing data shows that chest masses of 182 , 171 , and $181 \mathrm{~kg}$ are survivable with communication possible. Masses of 284 and $320 \mathrm{~kg}$ were fatal.

\section{Discussion}

We believe that this is the first model to estimate the mass or force required for flail chest from traumatic 
chest compression. To put our results into context, we consider two types of chest compression loading, dynamic and static.

\section{Dynamic load}

Our model predicts that a dynamic load of $4050 \pm 320 \mathrm{~N}$ is sufficient to cause flail chest. This force is consistent with fatalities from dynamic loading compression asphyxia from tipped soda machines, which can deliver $10-20 \mathrm{kN}$ when fully loaded. ${ }^{16-18}$ Dynamic cadaver compression studies show that rib fractures begin very early $(\sim 10 \mathrm{~ms})$ and well before maximum deformation. ${ }^{35}$ Hence the duration is not a critical factor for high-energy impact chest compressions.

The lethal dynamic force is actually higher than the lethal static force. That is because the ribcage does better at absorbing the initial force of a dynamic load than the eventual static load. Thus, the presence of injury consistent with causing flail chest due to the dynamic application of force signifies the application of more than $3500 \mathrm{~N}$.

\section{Static load ( $<4$ minutes)}

Our biomechanical modeling suggests that a static force of at least $2550 \pm 250 \mathrm{~N}(260 \pm 26 \mathrm{~kg})$ is required for flail chest. This compares well with the few recorded cases in which $180 \mathrm{~kg}$ was survived but $260 \mathrm{~kg}$ was not.

We also note that Hawes' chronic symptoms of difficulty with "devotions" (presumably chanting or praying) suggest that he had some broken ribs after a static load of $113 \mathrm{~kg}$. Spiggot's reduction to diaphragmatic ("lower part of the stomach") breathing is consistent with having some broken ribs with $204 \mathrm{~kg}$ but not with $180 \mathrm{~kg}$. This suggests that $113-204 \mathrm{~kg}$ was sufficient to break some ribs - depending on the individual and the application method-but not enough to cause flail chest. Bilateral rib fractures commonly occur during cardiopulmonary resuscitation (CPR) involving manual chest compressions. CPRrelated chest compressions reportedly deliver a concentrated force of about $644 \mathrm{~N}(66 \mathrm{~kg})$ and CPR results in rib fractures only about $8-31 \%$ of the time, mostly in older patients. ${ }^{36-38}$ Note that our model did not consider the effects of osteopenia or osteoporosis, which are often seen in elderly subjects.

The USA National Football League injury statistics were recently published. ${ }^{39}$ Counting practices and games from 2000 to 2010 there were a total of 31,338 injuries that resulted in players leaving a game or practice. Minor sprains, bruises and other trivial injuries were not included. There were in total two rib injuries. Since the American version of football often involves large body-piles, these data suggest that it is very difficult to generate flail chest from the weight of other humans.
It is interesting to compare our results with those obtained during embalmed cadaver studies done for automobile safety testing. ${ }^{35}$ A somewhat distributed force was used to simulate compression from a steering-wheel center-section by applying a $15 \mathrm{~cm}$ diameter load. Fractures were minimal up to $3.3 \mathrm{kN}(338 \mathrm{~kg})$. This value is $29 \%$ higher than ours, and it is not clear if the difference is due to the use of embalmed cadavers, the rate of loading, or the force distribution. Volunteers tolerated chest compressions involving $20 \%$ displacement with no injury, and the cadavers showed rib fractures beginning above that $20 \%$ level ending in flail chest at $40 \%$ compression. ${ }^{35}$

\section{Long-term static load ( $\geqslant 4$ minutes)}

Our model says nothing about long-term $\geqslant 4$ minute moderate chest compression crowd crush. ${ }^{40,41}$ The fatality mechanism generally does not involve flail chest, but rather prolonged hypoxia from restricted breathing. ${ }^{42,43}$

\section{Limitations}

Although a threshold injury limit conceptually exists, due to the natural variability of mechanical tissue properties and the huge range of body anthropometry, it is unlikely that a single value of load characterizes flail chest from traumatic compression. Furthermore, historical accounts of weights and measures can be questioned, and care should be used before accepting the historical numbers at face value. We did not model the female ribcage and would expect different results for females. ${ }^{44}$ Similarly, different results are expected from diseased ribs, notably those that are osteoporotic.

Our model assumed a supine subject. Since the modeled fractures (and most of those from existing case series) occurred in the ribs - and not the sternum - we do not feel that a prone position would change the results significantly. If anything, the costovertebral junction hinging should tend to allow greater weights on the back before fractures. Our results do not speak to eccentric loads including those seen with a subject on their side. Further limitations of the model are discussed at the end of the Modeling Methods section.

Our criterion of rib and sternum failure is stress. In many finite element models applied the strain is used as the criterion of failure. ${ }^{45}$ We did not give-agedependent results; rib strength decreases by about $22 \%$ from age 20 to age $50 .{ }^{46}$

\section{Conclusions}

A biomechanical ribcage model predicts that an adult male requires at least $2550 \pm 250 \mathrm{~N}(260 \pm 26 \mathrm{~kg})$ of static chest mass to cause flail chest. This is consistent with the records of judicial pressing. The model 
predicts that an adult male requires $4050 \pm 320 \mathrm{~N}$ of dynamic force to cause flail chest.

\section{Acknowledgments}

We wish to thank Andrea McKenzie, PhD, Professor of History (University of Victoria, Australia) for help with sources and permission to paraphrase some of her historical pressing cases.

\section{Declaration of conflicting interests}

Drs. Kroll, Nueman, and Graham have been experts in lawenforcement litigation.

\section{Funding}

This research did not receive any specific grant from funding agencies in the public, commercial, or not-for-profit sectors.

\section{References}

1. Karch SB, Brave MA and Kroll MW. On positional asphyxia and death in custody. Med Sci Law 2016; 56: 74-75.

2. Sathyavagiswaran L, Rogers $\mathrm{C}$ and Noguchi TT. Restraint asphyxia in in-custody deaths. Medical examiner's role in prevention of deaths. Leg Med (Tokyo) 2007; 9: 88-93.

3. K. Glatter and S. B. Karch, "Positional asphyxia: inadequate oxygen, or inadequate theory?. Forensic Sci Int 141, 201-2, May 102004.

4. Chan TC, Vilke GM and Neuman T. Restraint position and positional asphyxia. Am J Forensic Med Pathol 2000; 21: 93.

5. Trnka J, Gesicki M, Suslo R, et al. Death as a result of violent asphyxia in autopsy reports. Adv Exp Med Biol 2013; 788: 413-416.

6. Fernando T and Byard RW. Positional asphyxia without active restraint following an assault. J Forensic Sci 2013; 58: 1633-1635.

7. Hayashi T, Buschmann C, Correns A, et al. Fatal positional asphyxia. Forensic Sci Med Pathol 2012; 8: 470-472.

8. Byard R. Issues in the classification and pathological diagnosis of asphyxia. Aus J Forensic Sci 2011; 43: 27-38.

9. Sauvageau A and Boghossian E. Classification of asphyxia: The need for standardization. J Forensic Sci 2010; 55: 1259-1267.

10. Conroy C, Stanley C, Eastman AB, et al. Asphyxia: A rare cause of death for motor vehicle crash occupants. Am J Forensic Med Pathol 2008; 29: 14-18.

11. Byard RW, Wick R and Gilbert JD. Conditions and circumstances predisposing to death from positional asphyxia in adults. J Forensic Leg Med 2008; 15: 415-419.

12. Velmahos GC, Vassiliu P, Chan LS, et al. Influence of flail chest on outcome among patients with severe thoracic cage trauma. Int Surg 2002; 87: 240-244.

13. Vega RS and Adams VI. Suffocation in motor vehicle crashes. Am J Forensic Med Pathol 2004; 25: 101-107.

14. Ahmed Z and Mohyuddin Z. Management of flail chest injury: Internal fixation versus endotracheal intubation and ventilation. J Thorac Cardiovasc Surg 1995; 110: 1676-1680.
15. Michalewicz BA, Chan TC, Vilke GM, et al. Ventilatory and metabolic demands during aggressive physical restraint in healthy adults. $J$ Forensic Sci 2007; 52: 171-175.

16. Cosio MQ and Taylor GW. Soda pop vending machine injuries: An update. J Orthop Trauma 1992; 6: 186-189.

17. Champa JR, Hennrikus WL, Gerardi JA, et al. Four cases of injury involving soda vending machines. $J$ Orthop Trauma 1989; 3: 64-67.

18. Cosio MQ. Soda pop vending machine injuries. JAMA 1988; 260: 2697-2699.

19. El-Jawahri RE, Laituri TR and Kim AS. Further validation of age-dependent FE models of a mid-sized male thorax. SAE Int $J$ Passenger Cars-Mechanical Syst 2012; 5: 552-566.

20. Zhou Q, Rouhana SW and Melvin JW. Age effects on thoracic injury tolerance. SAE Technical Paper, 1996.

21. Kuppa SM and Eppinger RH. Development of an improved thoracic injury criterion. SAE Technical Paper, 1998.

22. Byard RW, Wick R, Simpson E, et al. The pathological features and circumstances of death of lethal crush/ traumatic asphyxia in adults - a 25-year study. Forensic Sci Int 2006; 159: 200-205.

23. Sklar DP, Baack B, McFeeley P, et al. Traumatic asphyxia in New Mexico: A five-year experience. Am J Emerg Med 1988; 6: 219-223.

24. McKenzie A. "This Death Some Strong and Stout Hearted Man Doth Choose": The practice of peine forte et dure in seventeenth- and eighteenth-century England. Law History Rev 2005; 23: 279-312.

25. Kroell CK, Schneider DC and Nahum AM. Impact tolerance and response of the human thorax II. In: Stapp Car Crash Conference Proceedings, 1974.

26. Vana PG, Neubauer DC and Luchette FA. Contemporary management of flail chest. Am Surg 2014; 80: 527-535.

27. Young W and Budynas R. Roark's Formulas for Stress and Strain, 7th ed. New York City, NY: McGraw Hill, 2002, pp.211-215.

28. Laurin LP, Jobin V and Bellemare F. Sternum length and rib cage dimensions compared with bodily proportions in adults with cystic fibrosis. Can Respir J 2012; 19: 196-200.

29. Carter DR and Hayes WC. Bone compressive strength: The influence of density and strain rate. Science 1976; 194: 1174-1176.

30. Yoganandan N and Pintar FA. Biomechanics of human thoracic ribs. J Biomech Eng 1998; 120: 100-104.

31. Kent R, Lessley D and Sherwood C. Thoracic response to dynamic, non-impact loading from a hub, distributed belt, diagonal belt, and double diagonal belts. Stapp Car Crash J 2004; 48: 495-519.

32. Murakami D, Kobayashi S, Torigaki T, et al. Finite element analysis of hard and soft tissue contributions to thoracic response: Sensitivity analysis of fluctuations in boundary conditions. SAE Technical Paper, 2006.

33. Griffin L and Kroll M. Rib-cage strength calculator. Available at: https://www.researchgate.net/ publication/311518699_Rib-cage_strength_calculator (2016).

34. Mush J. A true report of the life and martyrdom of Mrs. Margaret Clitherow. In: Morris $\mathrm{J}$ (ed.) The 
Troubles of Our Catholic Forefathers Related by Themselves. London: Burns and Oates, 1877, p.432.

35. Kroell C. Thoracic response to blunt frontal loading. In: Society of Automotive Engineers (ed.) The Human Thorax-Anatomy Injury and Biomechanics. Warrendale, PA: Society of Automotive Engineers, 1976, p.67.

36. Baubin M, Kollmitzer J, Pomaroli A, et al. Force distribution across the heel of the hand during simulated manual chest compression. Resuscitation 1997; 35: 259-263.

37. Oschatz E, Wunderbaldinger $P$, Sterz F, et al. Cardiopulmonary resuscitation performed by bystanders does not increase adverse effects as assessed by chest radiography. Anesth Analg 2001; 93: 128-133.

38. Krischer JP, Fine EG, Davis JH, et al. Complications of cardiac resuscitation. Chest 1987; 92: 287-291.

39. Mall NA, Buchowski J, Zebala L, et al. Spine and axial skeleton injuries in the National Football League. Am J Sports Med 2012; 40: 1755-1761.

40. Gill JR and Landi K. Traumatic asphyxial deaths due to an uncontrolled crowd. Am J Forensic Med Pathol 2004; 25: 358-361.
41. Hopkins I, Pountney S, Hayes P, et al. Crowd pressure monitoring. In: Smith RA and Dickie J (eds) Engineering for Crowd Safety. Elsevier, 1993, pp.389-398.

42. Seabrook J. Crush point: When large crowds assemble, is there a way to keep them safe? New Yorker Feb 2011, p.32-38.

43. DeAngeles D, Schurr M, Birnbaum M, et al. Traumatic asphyxia following stadium crowd surge: Stadium factors affecting outcome. WMJ 1998; 97: 42-45.

44. Bellemare F, Fuamba $\mathrm{T}$ and Bourgeault A. Sexual dimorphism of human ribs. Respir Physiol Neurobiol 2006; 150: 233-239.

45. Li Z, Kindig MW, Kerrigan JR, et al. Rib fractures under anterior-posterior dynamic loads: Experimental and finite-element study. J Biomech 2010; 43: 228-234.

46. AM Agnew, K Moorhouse, M Murach, et al. Tensile stress in human ribs throughout the lifespan. In: Proceedings of IRCOBI Conf. IRC-14-44, 2014. 